\title{
The boron effect on low temperature luminescence of $\mathrm{SrAl}_{2} \mathrm{O}_{4}: \mathrm{Eu}$, Dy
}

\author{
Virginija Vitola*, Ivita Bite, Donats Millers, Aleksejs Zolotarjovs, Katrīna Laganovska, \\ Krisjanis Smits, Agnese Spustaka
}

Institute of Solid State Physics, University of Latvia, Latvia

\section{A R T I C L E I N F O}

\section{Keywords:}

Persistent luminescence

Long afterglow

\begin{abstract}
A B S T R A C T
Temperature dependence of the afterglow of persistent luminescence material $\mathrm{SrAl}_{2} \mathrm{O}_{4}: \mathrm{Eu}$,Dy is a major problem for outdoor low temperature applications. Therefore this publication deals with tailoring the material for better outdoor use by exploring the second mechanism, that is involved in the afterglow - charge tunnelling from the trapping center to the luminescence center. Structure, morphology, emission and thermally stimulated luminescence properties have been measured for $\mathrm{SrAl}_{2} \mathrm{O}_{4}$ :Eu,Dy samples with different added boron percentage. The results indicate a change in morphology of the samples with increasing boron concentration, as well as a change in afterglow times. The low temperature luminescence intensity and afterglow time dependence of boron addition turns out to be different from the room temperature luminescence intensity and afterglow time dependence from boron concentration. Boron addition in necessary amount plays a key role to creating trapping centers in the material that are located spatially close to the luminescence center thus making the material afterglow possible even in low temperatures.
\end{abstract}

\section{Introduction}

$\mathrm{SrAl}_{2} \mathrm{O}_{4}$ :Eu,Dy is a very efficient green-emitting phosphor, its longlasting afterglow can be observed for hours after the termination of excitation [1-3]. Therefore, $\mathrm{SrAl}_{2} \mathrm{O}_{4}$ : $\mathrm{Eu}$,Dy is widely used in many applications - emergency signs, watch dials, luminous paints, luminescent coatings, in vivo imaging [2-6]. The problem that will be highlighted in this publication, is the temperature dependence of the afterglow of this material. Due to the shape and position of thermally stimulated luminescence (TSL) peak, $\mathrm{SrAl}_{2} \mathrm{O}_{4}$ : $\mathrm{Eu}$,Dy loses a lot of its afterglow efficiency in temperatures below zero Celsius, that is a major problem for material outdoor use [2,7]. However, there might be a solution for this problem, that is worth looking in to. This solution is closely related to the afterglow mechanism of the luminophore. There is strong evidence confirming the fact that $\mathrm{Eu}^{2+}$ is the luminescence center in $\mathrm{SrAl}_{2} \mathrm{O}_{4}$ responsible for the blue/green emission [8]. The $\mathrm{Eu}^{2+}$ changes its charge state during excitation, the electron from $\mathrm{Eu}^{2+}$ is transferred to some unidentified trap [2] and a number of traps are filled. The gradual thermally stimulated release of electrons from traps takes place at room temperature (RT). The released electrons recombine with $\mathrm{Eu}^{3+}$ ion, thus resulting in excited $\mathrm{Eu}^{2+}$ creation. The following radiative transition to the $\mathrm{Eu}^{2+}$ ground state is the origin of the green luminescence observed [2]. However, in addition to thermally stimulated process, the creation of excited $\mathrm{Eu}^{2+}$ luminescence centre via electron tunnelling was observed recently as well [9-11]. Thus, both processes can contribute in creation of an excited $\mathrm{Eu}^{2+}$ luminescence center. As the electron tunnelling process is not temperature dependent, but rather the spatial distribution dependent, it is expected that the afterglow at low temperatures could be enhanced by altering the fraction of traps located closely enough to the luminescence center for tunnelling process (Fig. 1).

Although the long persistent luminescence in strontium aluminates has been well-known for over two decades [1], the role of boron addition in extending the afterglow is still not well understood. In this research we focus on the role of boron addition to enhancing the tunnelling luminescence contribution in the afterglow mechanism.

\section{Experimental}

Strontium nitrate $\left(\mathrm{Sr}\left(\mathrm{NO}_{3}\right)_{2}\right.$, purity $98 \%$, Sigma Aldrich), aluminium nitrate nonahydrate $\left(\mathrm{Al}\left(\mathrm{NO}_{3}\right)_{3} \cdot 9 \mathrm{H}_{2} \mathrm{O}\right.$, purity $99,6 \%$, VWR Prolabo Chemicals) \%), europium oxide $\left(\mathrm{Eu}_{2} \mathrm{O}_{3}\right.$, purity $99,99 \%$, Alfa Aesar), dysprosium oxide ( $\mathrm{Dy}_{2} \mathrm{O}_{3}$, purity $99,9 \%$, Alfa Aesar), and boric acid $\left(\mathrm{H}_{3} \mathrm{BO}_{3}\right)$ were used as the starting materials for $\mathrm{SrAl}_{2} \mathrm{O}_{4}$ : Eu, Dy, B. Urea $\left(\mathrm{NH}_{2} \mathrm{CONH}_{2}\right.$, purity $99,5 \%$, Sigma Aldrich) was used as a chelating and a gelling agent. Nitric acid $\left(\mathrm{HNO}_{3}\right.$, assay $65 \%$, Sigma Aldrich) was used for dissolving $\mathrm{Eu}_{2} \mathrm{O}_{3}$ and $\mathrm{Dy}_{2} \mathrm{O}_{3}$. All chemicals were used without any further purification.

\footnotetext{
* Corresponding author.

E-mail address: virginija.vitola@cfi.lu.lv (V. Vitola).
} 


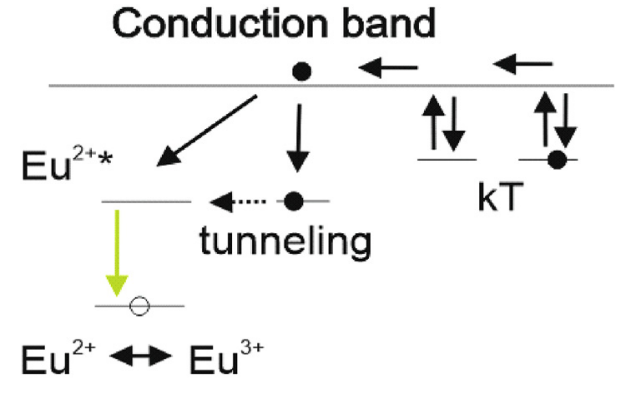

\section{Valence band}

Fig. 1. The possible mechanism of afterglow, that accounts for the luminescence afterglow in low temperatures [9].

In the present work, $\mathrm{SrAl}_{2} \mathrm{O}_{4}$ samples doped with $\mathrm{Eu}$, Dy and $\mathrm{B}$ were synthesized by using sol-gel method. 1 at\% Eu, 2 at\% Dy $\mathrm{SrAl}_{2} \mathrm{O}_{4}$ samples were prepared with six different concentrations (0-15 at \%) of the B. The appropriate amount of $\mathrm{Eu}_{2} \mathrm{O}_{3}$ and $\mathrm{Dy}_{2} \mathrm{O}_{3}$ were dissolved in $2 \mathrm{~mL}$ of $\mathrm{HNO}_{3}$ and the appropriate amount of $\mathrm{Sr}\left(\mathrm{NO}_{3}\right)_{2}, \mathrm{Al}\left(\mathrm{NO}_{3}\right)_{3}$. $9 \mathrm{H}_{2} \mathrm{O}$, and $\mathrm{H}_{3} \mathrm{BO}_{3}$ were dissolved in deionized water. After all starting materials were dissolved completely and the resulting solutions were combined, an appropriate amount of urea was added to the solution (the molar ratio of all metals ions and urea was 1:20, respectively). Also, an appropriate amount of deionized water was added so the molar concentration of all metals ions in the solution would be $0.2 \mathrm{M}$. Then this mixture was heated at $90{ }^{\circ} \mathrm{C}$ until white gel was formed. When the gel consistency was obtained, the gel was heated to $400{ }^{\circ} \mathrm{C}$ with a heating rate $13{ }^{\circ} \mathrm{C} \mathrm{min}{ }^{-1}$ in an open oven for $2 \mathrm{~h}$ for elimination of nitric oxides and a white powder was obtained. After synthesis, the obtained samples were pre-calcined at $850{ }^{\circ} \mathrm{C}$ for $2 \mathrm{~h}$ with a heating rate of $5{ }^{\circ} \mathrm{C} \mathrm{min}{ }^{-1}$ in the air to eliminate the organic materials and then calcined at $1300{ }^{\circ} \mathrm{C}$ for $3 \mathrm{~h}$ with a heating rate of $5{ }^{\circ} \mathrm{C} \mathrm{min}{ }^{-1}$ in a reductive atmosphere $\left(95 \% \mathrm{Ar} / 5 \% \mathrm{H}_{2}\right)$. Then the samples were naturally cooled down to room temperature and white to yellowish-green powders were obtained.

The crystallinity of all our strontium aluminate samples after the reducing heat treatment were characterized by X-ray powder diffraction (XRD, Rigaku MiniFlex $600 \mathrm{X}$-ray diffractometer) using a cathode voltage of $40 \mathrm{kV}$ and current of $15 \mathrm{~mA}$ with $\mathrm{Cu} \mathrm{K} \alpha$ radiation. XPS was measured with ESCALAB $250 \mathrm{Xi}$, using $\mathrm{Al} \mathrm{Ka}$ radiation. The morphology of all our strontium aluminate samples was characterized by scanning electron microscopy (SEM, Tescan Lyra) operated at $15 \mathrm{kV}$. Before the examination, the sample was coated with a gold layer.

For emission spectra and thermally stimulated luminescence spectra measurements the temperature of the samples was controlled by Sumitomo HC-4 closed-cycle helium cryostat operating within temperature range $\sim 9-325 \mathrm{~K}$. The Lake Shore 331 Temperature controller was used for temperature control as well as for sample heating (6 K/ min) during thermally stimulated luminescence (TSL) measurements up to $320 \mathrm{~K}$. Luminescence spectra were recorded using Andor Shamrock B303-I spectrometer. The samples were excited by X-rays. The excitation source was X-ray tube with $\mathrm{W}$ target $(30 \mathrm{kV}, 10 \mathrm{~mA})$.

\section{Results and discussion}

The structure of all our strontium aluminate samples before and after the reducing heat treatment was characterized by X-ray powder diffraction (Fig. 2). The Rietvald analysis of the XRD data showed that the major fraction of the samples is in $\mathrm{SrAl}_{2} \mathrm{O}_{4}$ phase, but it does have an admixture of $\mathrm{Sr}_{4} \mathrm{Al}_{14} \mathrm{O}_{25}$ phase (Fig. 3.), which increases with increasing boron concentrations. The secondary phase existence is also mentioned in Refs. $[12,13]$. We calculated the crystallite size from the

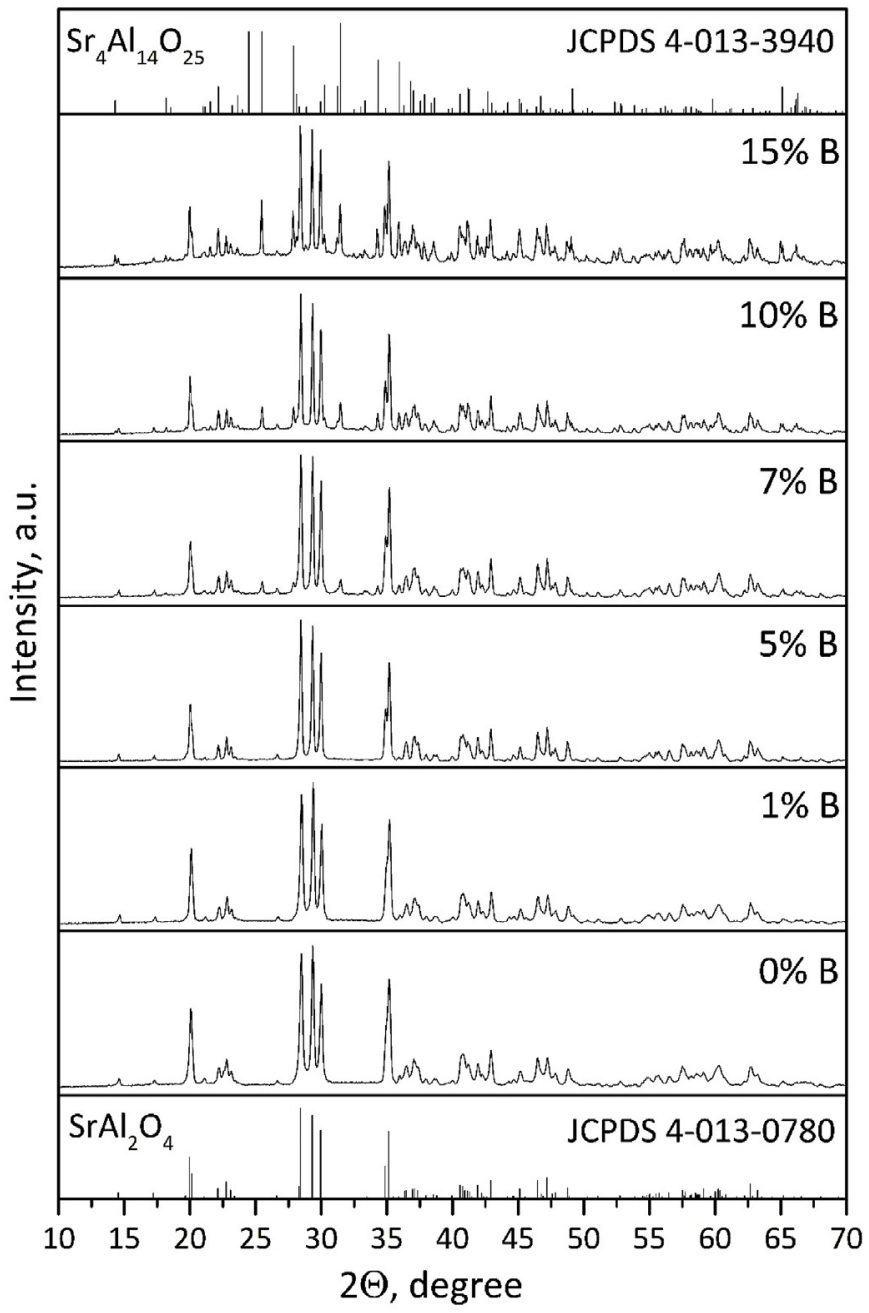

Fig. 2. XRD patterns of $\mathrm{SrAl}_{2} \mathrm{O}_{4}$ : Eu, Dy samples with different concentration of $\mathrm{B}^{3+}$.

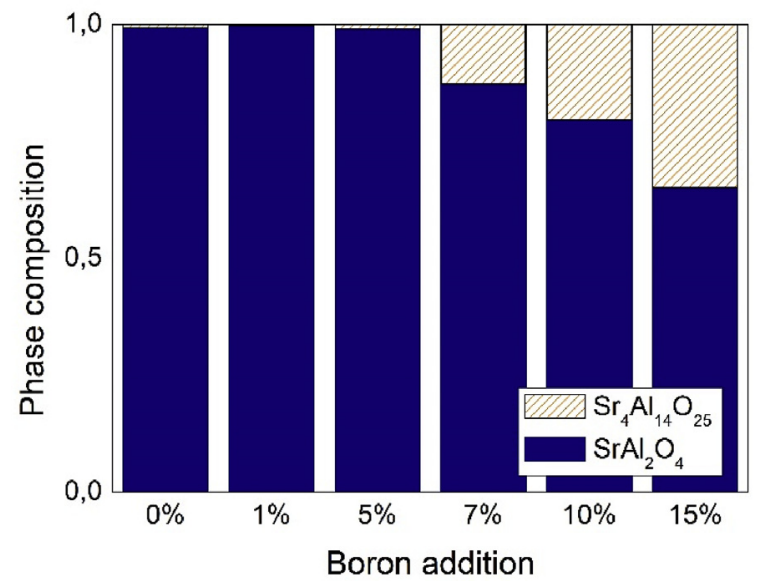

Fig. 3. Phase composition in sample dependence of boron at $\%$ addition.

XRD data and it can be observed that the size increases with increased boron concentration.

The SEM micrographs (Fig. 4) show that the morphology of the samples changes significantly as the added boron concentration increases. As boron concentration increases, grain and agglomerate sizes tend to increase as well as the structure of the samples becomes more homogeneous, compact and denser with smoother surface morphology. 


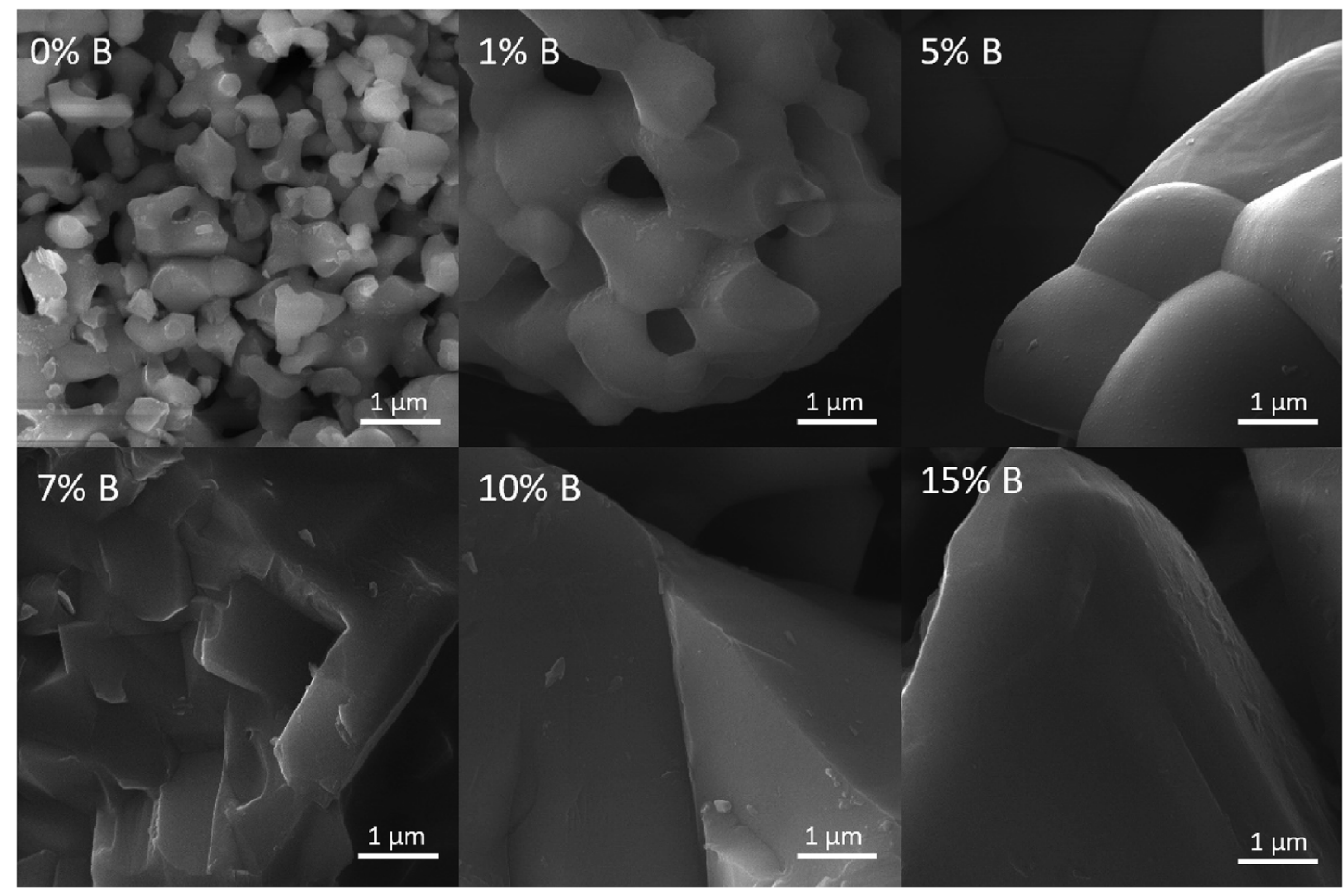

Fig. 4. SEM micrographs of $\mathrm{SrAl}_{2} \mathrm{O}_{4}$ : Eu, Dy samples with different concentration of $\mathrm{B}^{3+}$ (magnification: $50 \mathrm{k}$ ).

This is because of the addition of boron to the samples decreases their melting point and formation temperature of the crystalline phase (see Table 1).

XPS measurements were carried out to determine the boron concentration in the samples (Table 2.). One can notice that boron concentration in the samples rises until it reaches 6 at\% concentration. Adding more than $7 \%$ B during synthesis does not contribute to larger boron content in the samples - it reaches a saturation. The XPS measurements were carried out for several times while etching the sample with argon ions in order to exclude the possibility that the measurements are related to the surface of the sample.

To begin our search for the most effective luminophore for low temperatures, we checked the boron concentration effect on the room temperature luminescence. The emission is a broad band with maximum wavelength at $530 \mathrm{~nm}$, as expected (Fig. 5.) and at temperatures lower than $150 \mathrm{~K}$ the second luminescence band centered at $460 \mathrm{~nm}$ appears. Boron addition does not alter the shape or maximum wavelength of the emission band, that is characteristic to the $\mathrm{Eu}^{2+}$ emission in strontium aluminate matrixes. The emission intensity at the maximum wavelength right after the termination of excitation is in Fig. 6.

As it can be seen, the boron addition greatly affects the afterglow intensity. Moreover, close afterglow intensity for samples containing boron concentration in raw material within range of $7 \%-15 \%$ is in

Table 1

The crystallite size dependence of the added boron concentration calculated from XRD data.

\begin{tabular}{lll}
\hline \multirow{2}{*}{ Added B, at $\%$} & \multicolumn{2}{l}{ Crystallite size, nm } \\
\cline { 2 - 3 } & $\mathrm{SrAl}_{2} \mathrm{O}_{4}$ & $\mathrm{Sr}_{4} \mathrm{Al}_{14} \mathrm{O}_{25}$ \\
\hline 0 & 39,05 & \\
1 & 40,92 & \\
5 & 46,83 & 51,98 \\
7 & 46,83 & 55,32 \\
10 & 52,57 & 59,14 \\
\hline
\end{tabular}

Table 2

The added boron concentrations during synthesis vs the XPS measured B concentration in samples.

\begin{tabular}{ll}
\hline Added B, at $\%$ & XPS measurement B, at $\%$ \\
\hline 0 & 0,00 \\
1 & 1,31 \\
5 & 3,70 \\
7 & 6,05 \\
10 & 6,09 \\
15 & 6,03 \\
\hline
\end{tabular}

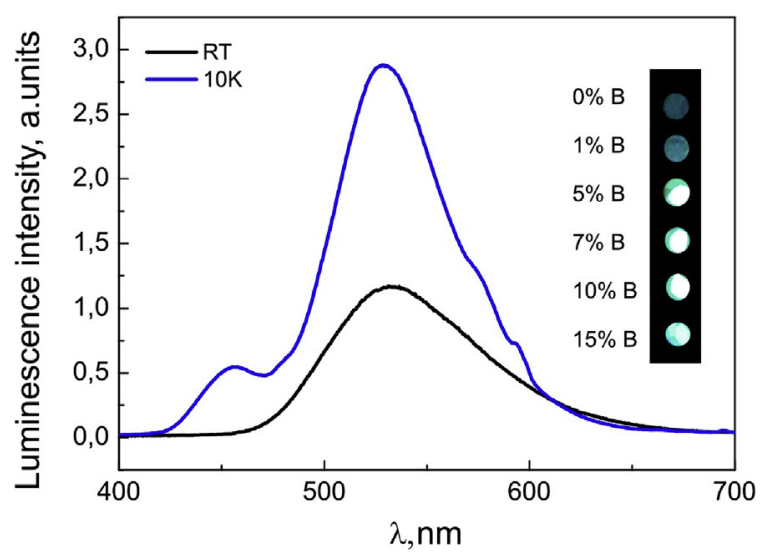

Fig. 5. The emission spectrum of $\mathrm{SrAl}_{2} \mathrm{O}_{4}$ : Eu, Dy with 5 at\% B addition right after the termination of excitation at room temperature and $10 \mathrm{~K}$ temperature.

agreement with XPS data in Table 2. As many articles have stated before [12,14], boron addition can prolong the intensity of the afterglow. Therefore the afterglow intensity dependence of time was measured in room temperature. Evaluated by human eye, the afterglow was not present after a minute after the termination of excitation in the samples with boron concentrations $0 \%$ and $1 \%$, whereas the samples with boron 


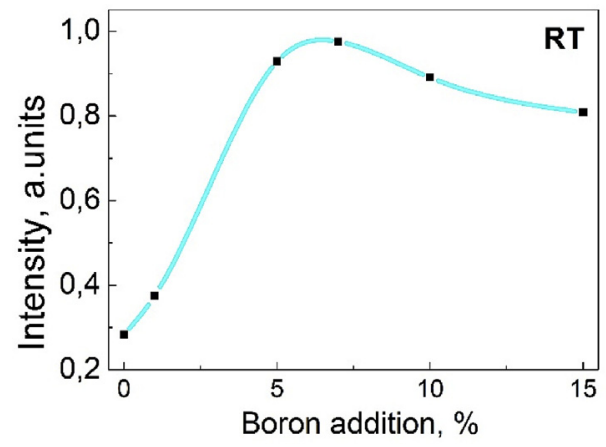

Fig. 6. The afterglow intensity right after termination of excitation measured in the maximum wavelength of emission in room temperature for samples with different B concentration.

concentrations 5, 7, 10 and 15\% were glowing for more than $10 \mathrm{~h}$ after the termination of excitation, as it was expected from the literature $[12,14]$. Concentrations of boron in range of $5 \%-15 \%$ lead to similar afterglow times and decay profiles.

The question now is - do the samples with these amounts of boron addition act similarly in low temperatures if compared to the afterglow in RT? To evaluate that, the samples were cooled down, irradiated and the afterglow was measured in $10 \mathrm{~K}$ temperature. As it turns out, the afterglow intensity right after the termination of excitation (Fig. 7.) and the afterglow time (Fig. 8.) in $10 \mathrm{~K}$ temperature differ from the results of room temperature measurements. The samples with boron concentration larger than $10 \%$ show no afterglow in low temperatures. This leads to the discussion on how are the trapping centers with higher boron concentrations different to those with lower concentrations? The answer should be related to the spatial distribution of trapping centers. We can assume that more trapping centers are created when adding boron above $1 \%$, but not all of these trapping centers are located spatially close to the luminescence center, therefore those located in greater distances can only be emptied with the help of thermal energy. One of the possibilities of the unknown electron trapping centers is the distorted $\mathrm{AlO}_{4}$ tetrahedra. There is experimental evidence of the presence of a substitutional $\mathrm{BO}_{4}$ unit in samples with boron addition [13]. Borate $\left(\mathrm{BO}_{4}\right)$ is more ionic in nature than $\mathrm{AlO}_{4}$ because of its smaller size and higher electronegativity of boron compared to Al [13]. This can also create lattice distortions, that can lead to electron trapping. Delgado et al. reports non-negligible local distortion of the cavities in $\mathrm{AlO}_{4}$ tetrahedra which takes place upon incorporation of boron [15].

We can conclude from the luminescence decay kinetics that the samples that are more of interest to us are the ones with 5, 7, 10 and $15 \%$ of boron addition, because the afterglow behaviour differs for those samples in low temperatures and RT. The 5\% and 7\% samples glow well both in low temperatures and RT, whereas the $10 \%$ and $15 \%$

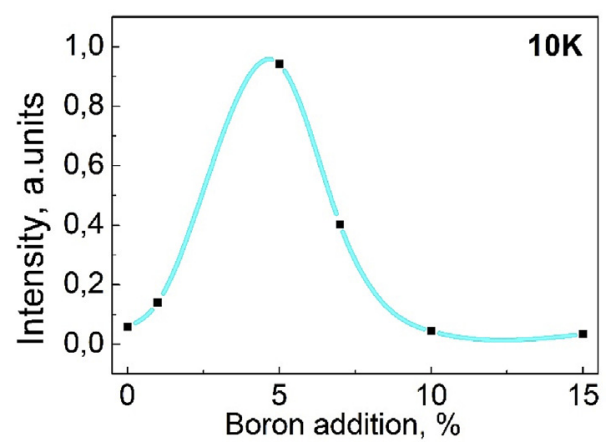

Fig. 7. The afterglow intensity right after termination of excitation measured in the maximum wavelength of emission in $10 \mathrm{~K}$ temperature for samples with different B concentration.

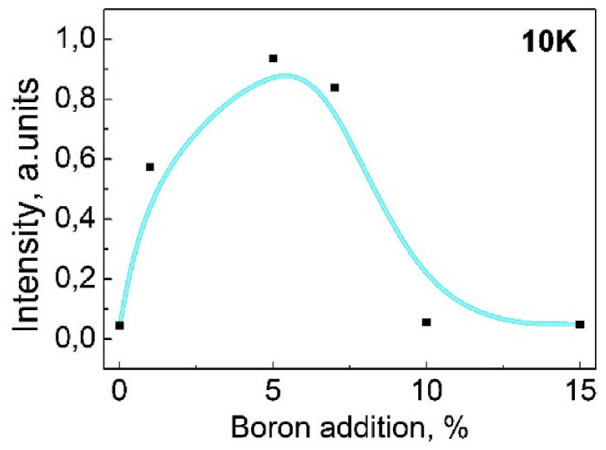

Fig. 8. The afterglow time in $10 \mathrm{~K}$ temperature for samples with different $\mathrm{B}$ concentration.

samples glow well only in RT. Therefore the TSL curves were compared for these samples. There are articles that have determined the shape of TSL curves above RT $[16,17]$. We also notice the dominant TSL maximum above room temperature, that is similar to all the samples and can be attributed to those trapping centers that are gradually emptied with thermal stimulation in RT. But the thing that differs for the abovementioned samples is the low temperature part of TSL (Fig. 9.).

The curves for $5 \%$ and $7 \%$ samples are similar and the curves for $10 \%$ and $15 \%$ are similar, therefore only one of each pair was depicted in Fig. 9 for clarity. The samples, that exhibit long afterglow in the low temperatures (with 5\% and 7\% boron addition), have several TSL peaks under room temperature. However, these peaks are non-existent in those samples, that do not exhibit long afterglow in low temperatures ( $10 \%$ and $15 \%$ boron addition). We can assume that with $5 \%$ boron addition some different trapping centers are created effectively. The $75 \mathrm{~K}$ peak is present also in the TSL curve of non-doped $\mathrm{SrAl}_{2} \mathrm{O}_{4}$ matrix and is attributed to the intrinsic defects of the material [18]. This peak is diminished with increasing boron concentration. The tail of lower temperature TSL peak reaches background value at $35 \mathrm{~K}$. Therefore the afterglow observed at $10 \mathrm{~K}$ is not due to the thermally stimulated release of electrons from traps. The initial part of $5 \%$ sample TSL curve $(10-25 \mathrm{~K})$ is not due to thermally stimulated charge carrier release from traps, but due to the tunnelling afterglow - this claim is backed by comparison of the decay kinetics in $10 \mathrm{~K}$ to the emission in time during TSL measurement and is also described in Ref. [11]. The afterglow intensity dependence on boron concentration at $10 \mathrm{~K}$ (Fig. 8) is the evidence that boron incorporation in $\mathrm{SrAl}_{2} \mathrm{O}_{4}$ : Eu, Dy leads to the formation of additional electron traps close to $\mathrm{Eu}^{2+}$. The tunnelling of electron from these traps to the Eu is possibly the case of the observed afterglow.

The decay kinetics in low temperature (Fig. 10.) are well approximated both with a sum of three exponents, that could point to the

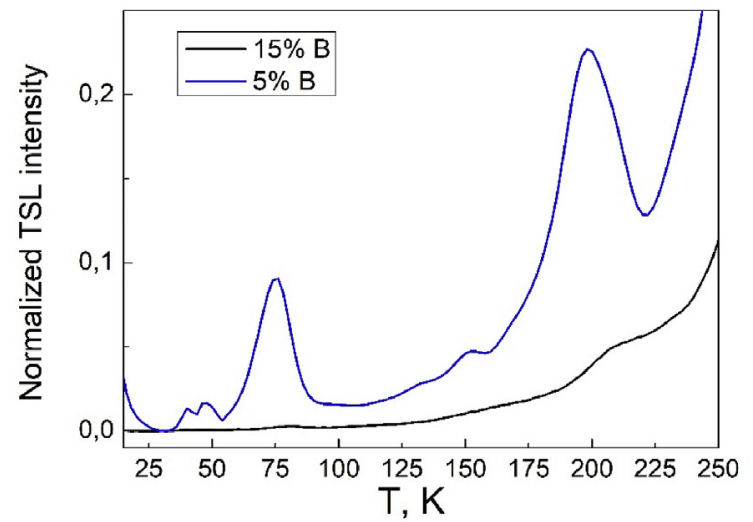

Fig. 9. The TSL glow curves for samples with $5 \%$ and $15 \%$ boron addition. 


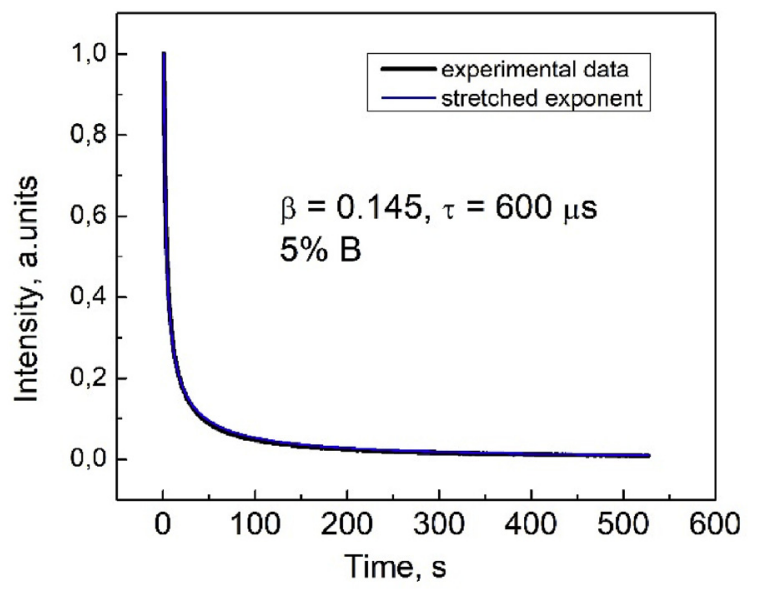

Fig. 10. Approximation of afterglow kinetics for sample with $5 \%$ boron.

existence of three distinct charge trapping sites, or the stretched exponential function

$I(t)=\exp \left(-\left(\frac{t}{\tau}\right)^{\beta}\right)$

where $0<\beta \leq 1$ and $\tau$ is a parameter with the dimensions of time [19]. The kinetics approximation with stretched exponent points out a charge trapping center distribution and the parameter $\beta$ denotes the extent of this distribution. In our case $\beta$ and $\tau$ were different for samples with various $B$ concentration, indicating, that the distribution for trapping centers in the samples, that glow well in low temperatures is wider than in those, that do not exhibit good afterglow in low temperatures.

\section{Conclusions}

The boron incorporation in the $\mathrm{SrAl}_{2} \mathrm{O}_{4}$ :Eu,Dy material contributes to the creation of trapping center, leading to prolonged afterglow times. However, these trapping centers are in spatially different positions some are located in such positions, that the tunnelling from the trapping center is possible, but some - located too far for the probability of tunnelling to be substantial. Adding boron above 7 at $\%$ in our experiments leads to the creation of spatially further located trapping centers, therefore the samples with large boron concentrations do not exhibit afterglow at lower temperatures. This leads to a conclusion that the luminophores can be modified intentionally to create long afterglow materials more suited for outdoor use.

\section{Declaration of competing interest}

囚 The authors declare that they have no known competing financial interests or personal relationships that could have appeared to influence the work reported in this paper.

\section{Acknowledgements}

V.V. acknowledges the financial support of ERDF PostDoc project
No. 1.1.1.2/VIAA/3/19/440 (University of Latvia Institute of Solid State Physics, Latvia) and K.S., I.B., A.Z., D.M. and K.L. acknowledge the financial support of ERDF, European-Union Project No.1.1.1.1/16/ A/182 (University of Latvia Institute of Solid State Physics, Latvia).

\section{References}

[1] T. Matsuzawa, A new long phosphorescent phosphor with high brightness, SrAl2O4:Eu2 +,Dy3 +, J. Electrochem. Soc. 143 (8) (1996) 2670, https://doi.org/ $10.1149 / 1.1837067$.

[2] V. Vitola, D. Millers, I. Bite, K. Smits, A. Spustaka, Recent progress in understanding the persistent luminescence in SrAl2O4:Eu,Dy, Mater. Sci. Technol. 35 (2019) 1661-1677, https://doi.org/10.1080/02670836.2019.1649802.

[3] J. Xu, S. Tanabe, Persistent luminescence instead of phosphorescence: history, mechanism, and perspective, J. Lumin. 205 (2019) 581-620, https://doi.org/10 1016/j.jlumin.2018.09.047.

[4] I. Bite, G. Krieke, A. Zolotarjovs, K. Laganovska, V. Liepina, K. Smits, K. Auzins, L. Grigorjeva, D. Millers, L. Skuja, Novel method of phosphorescent strontium aluminate coating preparation on aluminium, Mater. Des. 160 (2018) 794-802, https://doi.org/10.1016/j.matdes.2018.10.021.

[5] A. Zolotarjovs, K. Smits, A. Krumina, D. Millers, L. Grigorjeva, Luminescent PEO coatings on aluminum, ECS J. Solid State Sci. Technol. 5 (2016) 150-153, https:// doi.org/10.1149/2.0401609jss.

[6] K. Smits, D. Millers, A. Zolotarjovs, R. Drunka, M. Vanks, Luminescence of Eu ion in alumina prepared by plasma electrolytic oxidation, Appl. Surf. Sci. (2015), https:// doi.org/10.1016/j.apsusc.2015.02.085.

[7] J. Botterman, P. Smet, Persistent phosphor SrAl2O4:Eu,Dy in outdoor conditions: saved by the trap distribution, Optic Express 23 (2015) 868-881, https://doi.org/ 10.1364/OE.23.00A868.

[8] M. Nazarov, M.G. Brik, D. Spassky, B. Tsukerblat, Crystal field splitting of 5d states and luminescence mechanism in SrAl2O4:Eu2 + phosphor, J. Lumin. 182 (2017) 79-86, https://doi.org/10.1016/j.jlumin.2016.10.015.

[9] V. Liepina, D. Millers, K. Smits, Tunneling luminescence in long lasting afterglow of SrAl2O4:Eu,Dy, J. Lumin. 185 (2017) 151-154, https://doi.org/10.1016/j.jlumin. 2017.01.011.

[10] M.L. Chithambo, A.H. Wako, A.A. Finch, Thermoluminescence of SrAl2O4:Eu2 +,Dy3 + : kinetic analysis of a composite-peak, Radiat. Meas. 97 (2017) 1-13, https://doi.org/10.1016/j.radmeas.2016.12.009.

[11] V. Liepina, D. Millers, K. Smits, A. Zolotarjovs, I. Bite, X-ray excited luminescence of SrAl2O4:Eu,Dy at low temperatures, J. Phys. Chem. Solid. 115 (2018) 381-385, https://doi.org/10.1016/j.jpcs.2017.12.040.

[12] S. Yoon, J. Bierwagen, M. Trottmann, B. Walfort, N. Gartmann, A. Weidenkaff, H. Hagemann, S. Pokrant, The influence of boric acid on improved persistent luminescence and thermal oxidation resistance of SrAl2O4:Eu2 +, J. Lumin. 167 (2015) 126-131, https://doi.org/10.1016/j.jlumin.2015.06.021.

[13] A. Nag, T.R.N. Kutty, Role of B2O3 on the phase stability and long phosphorescence of SrAl2O4:Eu,Dy, J. Alloys Compd. 354 (2003) 221-231, https://doi.org/10.1016/ s0925-8388(03)00009-4.

[14] G.I. Akmehmet, S. Sturm, L. Bocher, M. Kociak, B. Ambrozic, C.W. Ow-Yang, Structure and luminescence in long persistence $\mathrm{Eu}$, Dy, and B codoped strontium aluminate phosphors: the boron effect, J. Am. Ceram. Soc. (2016) 1-6, https://doi. org $/ 10.1111 /$ jace.14188.

[15] T. Delgado, S. Ajoubipour, J. Afshani, S. Yoon, B. Walfort, H. Hagemann, Spectroscopic properties of Dy3 + - and Dy3+, B3+- doped SrAl2O4, Opt. Mater. 89 (2019) 268-275, https://doi.org/10.1016/j.optmat.2019.01.013.

[16] Y.H. Wang, X.Y. Song, S.H. Zhang, Effect of B2O3 on long-last phosphorescence of SrAl2O4:Eu2 + ,Dy3 +, Mater. Sci. Forum 610-613 (2009) 403-407 https://doi. org/10.4028/www.scientific.net/msf.610-613.403.

[17] H.N. Luitel, T. Watari, R. Chand, T. Torikai, M. Yada, Giant improvement on the afterglow of Sr4Al14O25:Eu2 +,Dy3 + phosphor by systematic investigation on various parameters, J. Mater. (2013), https://doi.org/10.1155/2013/613090.

[18] V. Vitola, D. Millers, K. Smits, I. Bite, A. Zolotarjovs, The search for defects in undoped SrAl2O4 material, Opt. Mater. 87 (2019) 48-52, https://doi.org/10.1016/j. optmat.2018.06.004.

[19] M.N. Berberan-Santos, E.N. Bodunov, B. Valeur, Mathematical functions for the analysis of luminescence decays with underlying distributions 1 . Kohlrausch decay function (stretched exponential), Chem. Phys. 315 (2005) 171-182, https://doi. org/10.1016/j.chemphys.2005.04.006. 